\title{
QUANTITATIVE TEXTURE ANALYSIS
}

\author{
Course of Advanced Instruction, \\ Islamabad, Pakistan, 4-8 March 1991
}

\author{
The course will be organized by: \\ Dr. A. Q. Khan Research Laboratories, Kahuta, \\ Dr. A. Q. Khan, Dr. Anwar ul Haq; \\ Department of Physical Metallurgy, TU Clausthal, FRG, \\ Prof. Dr. H. J. Bunge
}

\section{SCOPE OF THE COURSE}

Progress in modern industry requires the improvement of "classical" materials as well as the development of new "advanced" materials. In the great majority these materials have a polycrystalline structure, i.e. they consist of a great number of crystallites, the properties of which are direction dependent (anisotropic). Hence, their macroscopic properties depend on the orientation distribution-the texture-of the material.

Preferred orientation of the crystallites may be advantageous as for instance in anisotropic magnets or HTc superconductors or it may be disadvantageous as in deep drawing sheet where it gives rise to earing.

It is the aim of the course to provide an introduction to textures in materials as well as an overview of their technological implications. This includes particularly the following topics:

1) Texture measurement by $x$-ray, neutron and electron diffraction as well as by light and electron microscopical methods

2) Quantitative evaluation of the measurements by orientation distribution functions

3) The influence of textures on the materials' properties

4) How textures evolve in a material during its production

The course will contain general introductory lectures, seminars and practical classes. It will deal with all kinds of materials i.e. metals, ceramics, polymers, and composites including geological materials such as rocks and ores. The course is intended for materials scientists as well as practical engineers, physicists, 
chemists, mineralogists and geologists. It does not presume any special knowledge or experience in textures besides the basic concepts of the structure of materials.

The course will be held in English.

For further information please contact:

Dr. Anwar ul Haq

Dr. A. A. Khan Research

Laboratories, Kahuta

P.O. Box 905

Rawalpindi, Pakistan

Fax: (051) 481987

Telex: PUFCO 5501
Prof. Dr. H. J. Bunge

Dept. of Physical Metallurgy

Grosser Bruch 23

D-3392 Clausthal-Zellerfeld

Tel.: (05323) 72-2244

Fax: (05323) 72-3500

Telex: 953828 tuclz d 